\title{
Research
}

\section{Efficient Conservation in a Utility-Maximization Framework}

\author{
$\underline{\text { Frank W. Davis }}^{1}, \underline{\text { Christopher Costello }}^{1}$, and David Stoms ${ }^{1}$
}

\begin{abstract}
Systematic planning for biodiversity conservation is being conducted at scales ranging from global to national to regional. The prevailing planning paradigm is to identify the minimum land allocations needed to reach specified conservation targets or maximize the amount of conservation accomplished under an area or budget constraint. We propose a more general formulation for setting conservation priorities that involves goal setting, assessing the current conservation system, developing a scenario of future biodiversity given the current conservation system, and allocating available conservation funds to alter that scenario so as to maximize future biodiversity. Under this new formulation for setting conservation priorities, the value of a site depends on resource quality, threats to resource quality, and costs. This planning approach is designed to support collaborative processes and negotiation among competing interest groups. We demonstrate these ideas with a case study of the Sierra Nevada bioregion of California.
\end{abstract}

Key Words: biodiversity; Sierra Nevada; California; conservation; cost-effectiveness; irreplaceability; planning; retention; scenario

\section{INTRODUCTION}

In an effort to protect native species and ecosystems from overexploitation by humans, public and private conservation organizations engage with landowners in complex property transactions ranging from outright purchase to easements or management agreements. The fiscal, social, and political stakes can be high, as illustrated by three recent publicly financed land acquisitions in California. In 1996, the state and federal governments agreed to pay MAXXAM, Inc., the parent company of Pacific Lumber Co., $\$ 380 \times 10^{6}$ to acquire the Headwaters Forest, 3036 ha of late seral redwood (Sequoia sempervirens) forest in northern coastal California (U.S. General Accounting Office 1998). In October 2003, the State of California committed $\$ 150 \times 10^{6}$ to purchase the Ahmanson Ranch, 1130 ha of grassland, woodland, and coastal scrub $30 \mathrm{~km}$ northwest of Los Angeles. A month earlier, the State committed $\$ 140 \times 10^{6}$ to purchase 77 ha of the Ballona Wetlands, a tidal marsh bordered by the cities of West Los Angeles and Venice. Taken together, these high-profile projects placed 4243 ha of land in public ownership at a cost of $\$ 670 \times 10^{6}$ or roughly $\$ 158,000 / \mathrm{ha}$ (\$63,900/acre).

In this paper, we develop and illustrate the application of a framework for making efficient conservation investments. The Headwaters Forest, Ahmanson Ranch, and Ballona Wetlands shared several traits of modern conservation projects that will be featured in this framework: the areas contained significant biological resources that were threatened by development or extractive activities, and public acquisition had broad public support and was championed by passionate and committed environmental groups. Nevertheless, the deals carried a high price tag, even by California standards, raising the question of whether public funds were well invested in terms of conservation "bang for buck" (California Legislative Analyst's Office 1996). Regardless of project size, all conservation efforts must address the same questions: Are we protecting the right places, and are we getting our money's worth?

Economists have advocated cost-effective analysis as a tool for setting conservation priorities (Ando et al. 1998, Metrick and Weitzman 1998, Hughey et al. 2003, Trousdale and Gregory 2004). Metrick and Weitzman (1998), in particular, argue that priorities 
must be assigned to conservation efforts based on a formal evaluation of biodiversity value, the conservation cost, and the degree to which conservation action will improve the likelihood of biodiversity persisting. By this logic, one can only evaluate the conservation value of a candidate site in the context of how the biodiversity of the site would change under alternative scenarios of land use and land management relative to the estimated cost associated with each scenario.

The methodological literature in reserve network selection has generally avoided using formal scenarios of land-use change and rarely specifies the fiscal cost of conservation actions. Instead, systematic conservation planning methods (Margules and Pressey 2000) have focused on achieving conservation "efficiency," either by minimizing the area required to meet specified conservation targets for species or habitat types or by maximizing the representation of habitats or species that can be achieved given a fixed area or number of sites that can be protected (Cocks and Baird 1989, Pressey et al. 1993, Church et al. 1996, Possingham et al. 2000, ReVelle et al. 2002). The implicit land-use scenario is that unprotected areas will not contribute to biodiversity persistence in the long run, prompting related research to ensure that conservation targets are set and reserve networks selected to best provide for the long-term persistence of species (Williams and Araujo 2000, Cabeza and Moilanen 2001, Rodrigues and Gaston 2001). Faith et al. (2001) provide a rare example of accounting for partial protection through sympathetic management outside of reserves. Land area is usually treated as a surrogate for cost, despite well known variations in land prices that are typically positively correlated with conservation threat (Ando et al. 1998). The results of selection models can change considerably when spatially explicit models of threatening landuse change are considered (White et al. 1997). Similarly, conservation priorities can change considerably when variations in land prices are taken into account (Ando et al. 1998).

During a 2-yr working group at the National Center for Ecological Analysis and Synthesis, we developed a planning model to help conservation funding agencies in California evaluate the costeffectiveness of conservation options. The planning model combines several aspects of existing conservation planning approaches. First, it requires the setting of explicit conservation goals for defined and measurable elements of biodiversity (Margules and Pressey 2000). Second, it uses a multicriterion scoring approach to characterize site resource quality (McHarg 1969, Keisler and Sundell 1997, Guikema and Milke 1999, Malczewski 2000, Theobald and Hobbs 2002). This is especially important for collaborative, publicly funded conservation projects that must accommodate the conservation preferences of a diverse range of agencies and stakeholders (Schmoldt and Peterson 2000, Theobald et al. 2000). Third, the model evaluates the benefit of conserving a site relative to the stated goal and status of all sites in criterionspecific "reference regions," thus following the recent tradition in systematic conservation planning to identify conservation networks that reflect globally optimal decisions (ReVelle et al. 2002). Fourth, our model presumes that there is a budgetary constraint on conservation and that the objective is to maximize the amount of conservation accomplished given that constraint (Church et al. 1996, ReVelle et al. 2002). Thus it implements the "benefits-loss-cost targeting" approach proposed by Newburn et al. (2005).

Our model is somewhat unusual because it combines aspects of multicriteria scoring and optimal set selection. It is most distinctive because, rather than seeking to maximize the amount of biodiversity that is added to the reserve system given the fixed budget, it maximizes the value of the biodiversity that remains in the region across both protected and unprotected lands at a specified time in the future. To do this, an explicit scenario of expected patterns of biodiversity loss with and without specified conservation investments is required. Instead of designing plans that achieve all stated conservation targets, we set conservation goals and measure the marginal gain in resource conservation from adding any individual site to the current system of conservation areas. The site's conservation value is calculated based on the incremental progress toward stated conservation goals and evaluated relative to the estimated cost of conserving that site. We formulate an objective function to maximize the total conservation "utility" remaining at the end of the planning period, which is based on the geography of threats and estimated site costs and is subject to a budget constraint. Utility, as used here, encompasses both use values, such as ecosystem services and resource commodities, and nonuse values, e.g., species existence. We show that this model is very general and can accommodate most existing systematic approaches to conservation planning. We also 
discuss how our marginal utility framework embraces and refines established concepts in conservation planning such as complementarity, efficiency, irreplaceability, and retention (Margules and Pressey 2000).

Our model is data-driven and requires spatially referenced biological and socioeconomic information as well as scenarios of future environmental change. We acknowledge that, in reality, conservation planners and decision makers must go beyond available spatial data and consider expert opinion as well as many intangibles related to socio-political feasibility, opportunities such as willing sellers, and indirect benefits, e.g., how one investment could create investment or management opportunities in other areas (Prendergast et al. 1999). Ultimately, good conservation decisions rest on the decisionmakers' experience and sound judgment. However, that judgment still depends on scientific data and information on the known geography of resource quality, threat, and conservation costs. Our model attempts to organize and render that information in the way that is the most useful to the decisionmaking process.

The details of our planning framework and its application to the Sierra Nevada region of California are presented in this paper. We focus on the conservation of native terrestrial biodiversity in the form of species, communities, and ecosystems, but the framework can also be applied to other conservation concerns such as aquatic biodiversity, commodity production lands (Machado et al. 2005), public open space, cultural resources, and recreational opportunities.

\section{SITE SCORING USING A MARGINAL VALUE APPROACH}

\section{Model overview}

The planning region is delineated and divided into fixed, nonoverlapping sites (Cocks and Baird 1989). The conservation planner must allocate a specified conservation budget to maximize the social value of the biodiversity remaining in the planning region at a specified time in the future. This requires sitespecific cost estimates for alternative conservation actions, e.g., no action, land acquisition, purchase of easements, stewardship agreements with private landowners, restoration activities. A conservation action is taken at a site to remove identified threats such as land development that would otherwise reduce resource values in the future. The effectiveness of the conservation action is a function of how much resource loss is averted by conserving the site. To determine this, the planner must estimate a change in total utility ascribed to the resource over the entire planning region that would result from a change in resource level at the site or set of sites. Utility is measured across one or more weighted, additive biodiversity attributes (e.g., Keisler and Sundell 1997).

Our approach rests on the following assumptions:

- resource quality, which is a function of biological composition, ecological condition, and spatial context, can be measured across space;

- we can ordinally rank the desirability of any given amount and distribution of resources across the planning region;

- we can predict the effect of a specified conservation activity, e.g., land purchase, easement purchase, on the future amount and distribution, and therefore social value, of resources and the effect of taking no action; and

- the cost of site conservation equates to the social value of the best alternative use.

Our framework bears a close resemblance to that of Hyman and Leibowitz (2001). They measure the conservation or restoration value of a site based on the level of "conservation effort" relative to the level of "ecological benefit" associated with change or avoided change in a particular resource at the site. Our formulation extends their approach to include the capacity not only to rank sites but also to evaluate alternative sets of sites in terms of net benefit. This is particularly relevant when the relationship between resource abundance and utility is nonlinear.

\section{Measurement of resource value}

A biodiversity resource is an observable feature or process used to evaluate biodiversity status relative to conservation goals such as the occurrence or number of individuals of a species, area of a habitat 
type, area of a reserve buffer, etc. We evaluate each resource of interest in every site in the region. If there are $K$ such resources, then we will assume that we need only keep track of this finite collection of resources to calculate utility. The conservation planner evaluates the expected level of each resource at some date $(T)$ in the future under one or more land-use scenarios. Denote by $y_{\mathrm{k}}$ the projected level of resource variable $k$ and by $Y=\left[y_{1}, y_{2}, \ldots\right.$, $y_{\mathrm{K}}$ ] the collection of these $K$ observation sets at time $T$. The fundamental assumption here is that the only items that need to be measured or forecast are the resources represented by $Y$, and therefore that $Y$ fully characterizes the state of this system at the end of the planning period.

We denote by $x$ a geographically referenced layer that depicts the conservation actions taken in the sites at time 0 . For example, if conservation is by fee-simple acquisition, $x$ indicates whether properties are to be acquired (1) or not (0). Conservation actions taken today $(x)$ have an effect on the level of resources at time $T\left(y_{1}, \ldots, y_{\mathrm{K}}\right)$. To make this link explicit, we express the future resource levels as follows: $Y(x)=\left[y_{1}(x), y_{2}(x), \ldots\right.$, $\left.y_{\mathrm{K}}(x)\right]$. We assume that all exogenous influences are embedded directly into $y_{\mathrm{k}}(x)$, and that there is no uncertainty.

\section{Valuation of resources}

Denote by $U(Y(x))$ the social value, i.e. utility, associated with the resources described by $Y$. Utility is a function only of the resources existing at time $T$, not the current status of resources. Determining the function $U($.$) is the most difficult, but it is$ nevertheless a critical component of our planning model, because writing the utility in this general way makes it easier to analyze a number of common conservation planning objectives.

Consider the hypothetical example depicted in Fig. 1. The top panel illustrates the utility associated with the amount of a particular resource $(U(y))$ expressed as a percentage of a conservation goal, $y^{*}=80$. In this particular function, utility is linearly related to $y$ for $0<y<30$ and concave for $30 \leq y<80$. Utility is satiated, i.e., maximized and constant, when $y>$ 80 . Figure 2 graphs the marginal utility, $U^{\prime}(y)$, which is the increase in utility associated with an increase in resource amount at a given level of the resource, i.e., the first derivative of $U(y)$.

Suppose that the current level of $y$ in the region is
32 and, in the absence of any conservation, the future level is projected to be 25 . Now consider taking conservation action $i$ that would prevent the loss of those seven units of the resource. The change in utility associated with this conservation action is calculated in Fig. 1 as the vertical distance $U(32)$ $U(25)$ or equivalently in Fig. 2 by the integral between $U^{\prime}(25)$ and $U^{\prime}(32)$.

\section{The effect of conservation on valuation}

We assume that the utility associated with $y$ at future time $T$ will be a function of the spatial distribution, composition, and condition of that resource at that time. We model the conservation action, $x$, as taking place only at the present time. In this way, today's conservation actions affect the future disposition of the resources of concern. By way of example, consider fee-simple acquisition as the conservation action. Based on a scenario of future development in the planning region, we predict that in the absence of conservation a particular site will be developed sometime during the planning period. Now suppose that acquiring the site will eliminate the risk of development and prevent any further loss of resources. In this case, calculating the marginal value of conserving the site is relatively straightforward. Calculating the effect of that conservation action on resources across the entire landscape is more complex. For example, it is possible that placing the parcel in reserve would influence the development of adjacent parcels. This kind of feedback can render counterproductive the initial conservation action, i.e., it may actually lead to a decrease in resource abundance rather than an increase. Although our framework can accommodate these kinds of complex interactions, establishing such structural relationships empirically is difficult.

\section{Optimal conservation decisions}

Provided that we can (1) measure the relevant resources $(Y),(2)$ know how any given conservation action will affect those resources $(Y(x))$, and (3) value the relative desirability of different future resource states $(U(Y(x)))$, then we have all the components needed to calculate optimal conservation decisions. In addition, if we can estimate the cost of each potential conservation action, we can trace out an indirect utility function that describes the maximum possible level of utility under different conservation budgets. 
Fig.1. A hypothetical conservation utility function.

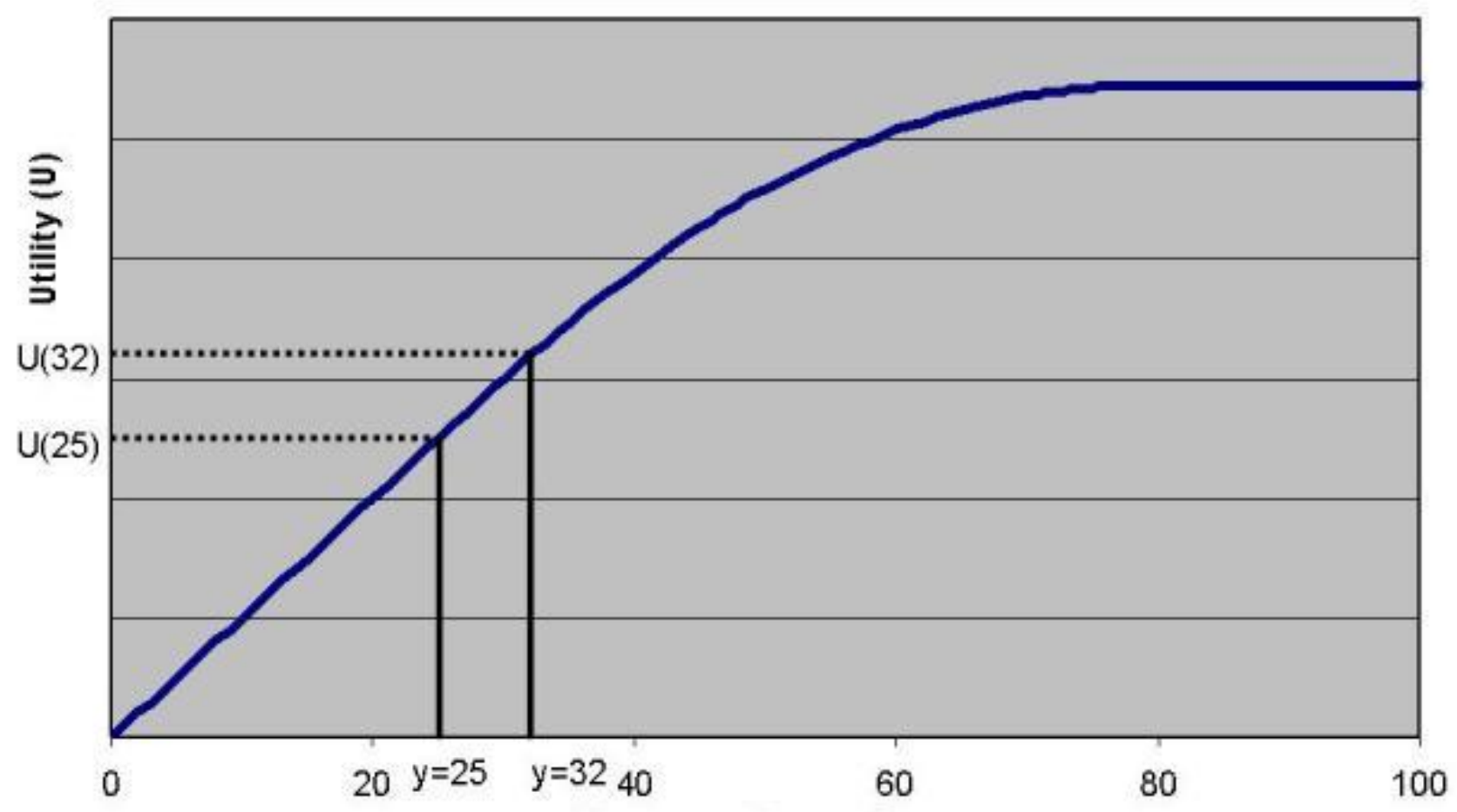

Resource amount

Denote by $I$ the number of possible conservation actions, which could be a combination of actions such as outright acquisition, the purchase of development rights, or the provision of stewardship incentives on different parcels in the planning region. For example, if we restrict attention to acquisition, then $I$ would be the number of parcels potentially up for sale. More generally, we can think of $I$ as the master list of possible conservation activities, and the conservation planner's job is to select some subset of those activities in which to invest. We denote by $C=\left[C_{1}, C_{2}, \ldots C_{\mathrm{I}}\right]$ the vector of costs associated with each of those potential conservation actions and by $C(x)$ the total cost of any particular portfolio of conservation actions, $x$. These are assumed to be additive in the sense that the total cost of conservation will be the sum of the costs associated with the chosen conservation actions.

The vector $x$ is some set of conservation actions in which to invest. For example, suppose $I=5$, so that there is a total of five possible conservation projects in which to invest, and the associated costs are $C=$ $\left[\begin{array}{lllll}1 & 4 & 10 & 11 & 20\end{array}\right]$. Then the total cost of conservation action $x$, if $x=\left[\begin{array}{lll}1 & 3 & 4\end{array}\right]$, is $C(x)=22$.

Formally, we would like to allocate a fixed budget $B$ toward those conservation actions that maximize the utility achieved at future date $T, U(Y(x))$. The objective is expressed mathematically as follows: 
Fig. 2. Marginal utility function derived from the function in Fig. 1.

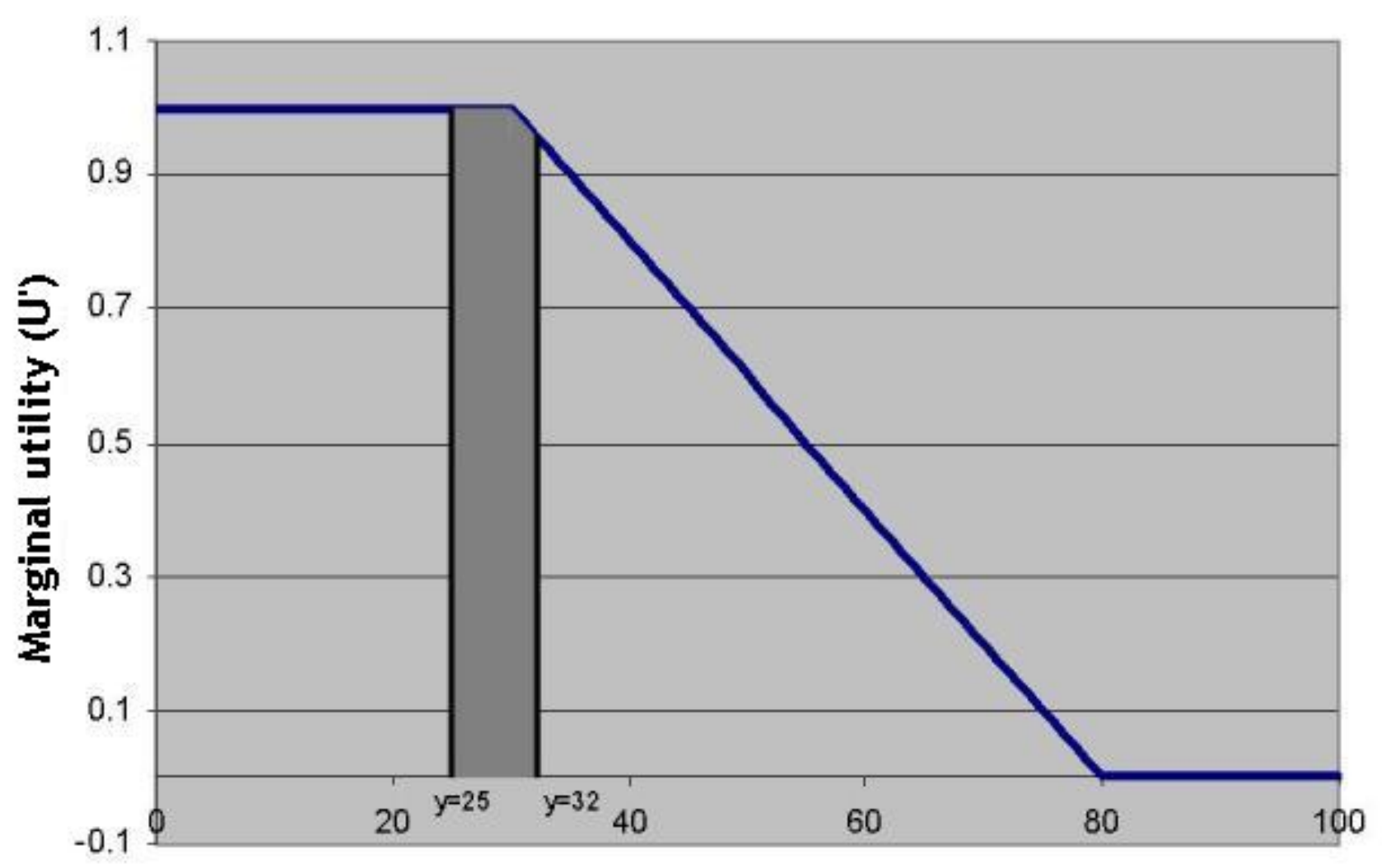

\section{Resource amount}

$$
\max _{x} U(Y(x))
$$

When subject to the budget constraint:

\section{$C(X)<B$ \\ MODEL APPLICATION}

To demonstrate the framework, we present a hypothetical planning exercise for the Sierra Nevada bioregion of California (Sierra Nevada Ecosystem Project 1996). Although our analysis is based on actual data and plausible conservation goals, criteria, and criteria weights, the results should not be construed as a conservation plan for the region, which would require far more extensive and inclusive consultations with stakeholders and a more thorough and detailed analysis of data and alternatives.

Conducting the exercise requires that we answer five conservation planning questions (modified from Steinitz 1990). 
1. What resources do we seek to conserve in the planning region, and what are our goals for those resources?

Based on discussions at a series of workshops at the National Center for Ecological Analysis and Synthesis and a review of the recent conservation planning literature, we identified five objectives that are commonly applied when assigning priorities to sites for conserving terrestrial biodiversity (see Davis et al. 2003 for details). These objectives are to: (1) conserve hotspots of rare, endemic, threatened, and endangered species (Dobson et al. 1997, Noss 2000); (2) conserve underrepresented species and community types (Cocks and Baird 1989, Pressey et al. 1993, Scott et al. 1993); (3) conserve extensive wildlands for large carnivores and other "area-dependent species" (Soule 1991, Noss 2000); (4) conserve biophysical landscapes to maintain ecological and evolutionary processes (Belbin 1993, Forman and Collinge 1996, Cowling and Pressey 2001); and (5) expand existing reserves (Cowling et al. 2003).

We developed algebraic functions to measure the conservation value of a planning site with respect to each of these five objectives. Additive weighted scoring was used to combine the values for a site. For brevity we describe the results for only three criteria here: 1,2 , and 5 . The derivation of these measures is described in Davis et al. (2003).

Goal setting for conservation and restoration is a social process that is often the most difficult step in designing conservation strategies. For demonstration purposes we invented plausible conservation goals for each of the resource criteria, although, in practice, because the model operates to maximize conservation benefits within a finite budget rather than to satisfy all goals, the shape of the utility functions can be more important than the specific quantitative goal. The goal for rare, threatened, and endangered species is to protect all known occurrences of these elements. The goal for underrepresented community types is to conserve an area proportional to their current extent and inversely proportional to the current condition of the type. By this logic, meeting the goal for highly degraded community types, e.g., many wetland and riparian types, could entail restoration, which could be considered a more expensive type of conservation action. No area goal was set for expanding existing reserves. Instead, we used the species-area curve (Rosenzweig 1996) as a basis for specifying a nonlinear, diminishing, marginal conservation value with increasing area. Thus, a site adjacent to a small reserve would score higher than a comparable site near a larger reserve.

2. What is the current extent and condition of those resources?

We adopted the State of Californial's definition of the Sierra Nevada bioregion, which is based on both ecological and political boundaries (Fig. 3). Sites were township quadrants from the Public Land Survey System. These roughly 5 x $5 \mathrm{~km}$ areas conform closely to broad patterns of land ownership and management, and their relatively uniform size and shape facilitates analysis of biodiversity patterns and spatial neighborhoods. California was divided into 18,234 sites, including 3154 sites in the Sierra Nevada bioregion (Fig. 4). Existing 1-ha resolution data on land cover, land use, land management, housing density, and roads, as well as occurrence data for threatened and endangered species, were compiled for each site.

Data on land management were obtained from the California Department of Forestry and Fire Protection (CDFFP). All lands mapped as "public," excluding public urban areas, or as "private reserved" were considered protected, and lands mapped as "private nonreserved" were considered unprotected. Current land-use/land-cover data were also obtained from CDFFP. Land cover was classified into 55 wildlife habitat types based on vegetation structure and dominant overstory species as defined by the California Wildlife Habitat Relationship system (Mayer and Laudenslayer 1988). To model road impacts we used 2000 TIGER data on road networks developed by the U.S. Census Bureau (2002).

In the autumn of 2002, statewide data on rare, threatened, and endangered (RTE) species were extracted from the California Natural 
Fig. 3. The Sierra Nevada bioregion of California (yellow lines) displayed on a shaded relief image. Internal yellow lines indicate poorly surveyed boundaries in the public land survey system; black lines indicate county names and boundaries.

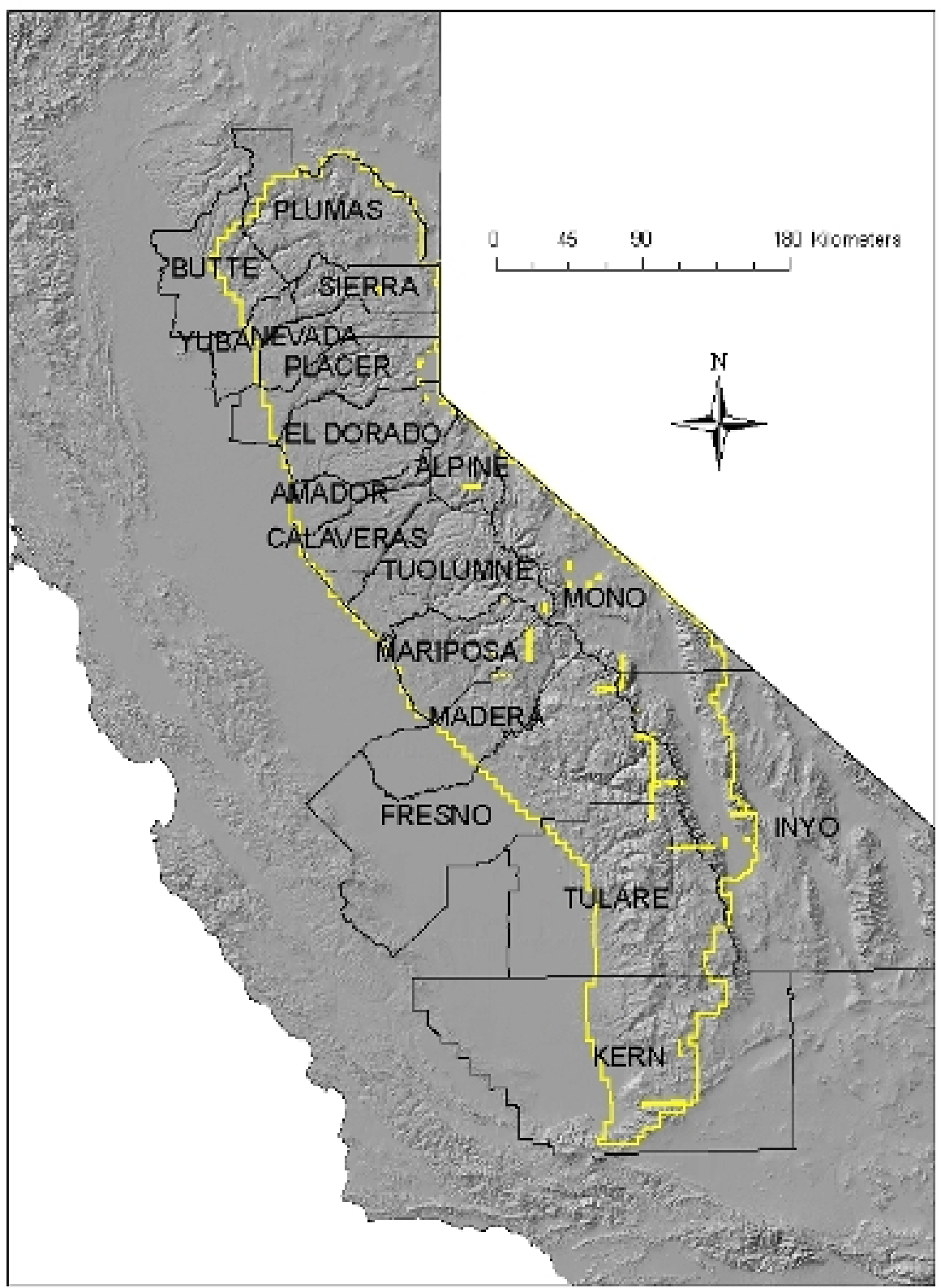


Fig. 4. Township quadrants used as planning sites in the Sierra Nevada bioregion, and the distribution of reserved vs. nonreserved lands.

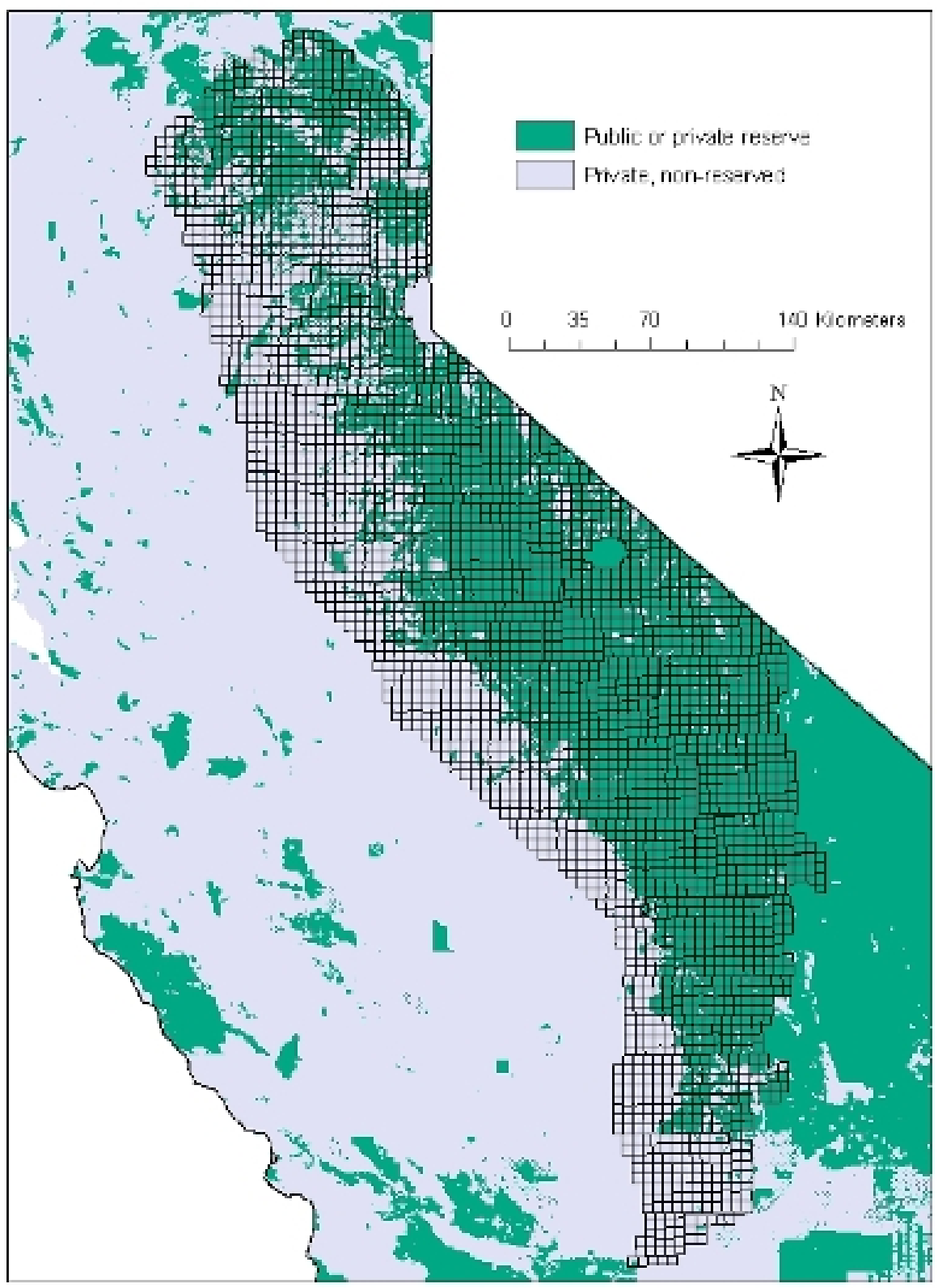


Diversity database, which is developed and maintained by the California Department of Fish and Game. For the purposes of this analysis, we recorded the presence of all species with conservation ranks of G1 (critically imperiled) and G2 (imperiled) in each planning unit. We included the entire State of California as the reference region for analyzing RTE species rather than just the Sierra Nevada. This minimized the effect on site scores of marginal occurrences of species that are more widely distributed in neighboring regions.

Ideally, ecological condition would be measured with respect to each element of biodiversity based on detailed ecological knowledge of species and ecological communities. For practical purposes, we developed a simple generic index of ecological condition that could be applied regionwide for all elements in the current as well as future time periods. The index is based on land conversion to urban or cultivated agriculture, housing density in nonurban areas, roads, and forest structure (Davis et al. 2003). Each 1-ha cell in the region was scored from 0 (worst) to 1 (best) for each factor.

For this exercise, we assigned a condition value of 0 to cells mapped as urban, cropland, orchards, or vineyards, although such lands can support significant native terrestrial biodiversity depending on the design and intensity of land-use practices (Germaine et al. 1998, Schwartz et al. 2002, Benton et al. 2003). It would be a simple modification to ascribe varying condition levels to urban and agricultural lands if information were available on site-specific management regimes and habitat conditions for native species. The condition score of suburban and rural residential areas was assumed to decline linearly with increasing housing density up to 1 house/ 2 ha, at which point the cell was classified as urban (Theobald et al. 1997). The effect of roads on cell condition varied as a function of road class, cell distance from the road, and predicted traffic volume (Forman and Deblinger 2000). For commercial forest types, the condition index varies from 0.33 for early seral forests to 0.66 for mid-seral forests to 1 for mid-to-late seral forests. To be in excellent ecological condition, a cell had to be all of the following: (1) nonconverted, (2) classified as low housing density, (3) unaffected by roads, and (4) of mid- or lateseral forest structure if supporting a commercially important forest type. Operationally, this equated to setting the condition score for the cell to the minimum of the scores for conversion, housing density, road impact, and forest structure.

Based on projected patterns of housing development, the condition index was mapped at 1-ha resolution for the years 2000 and 2040. Because our purpose was only to demonstrate the planning model, we did not measure the uncertainty or scale sensitivity in input factors or in the overall index. When calculating habitat area, e.g., the area of sites occupied by an RTE species or the extent of a wildlife habitat type, we multiplied each 1ha cell by its condition index before summing all cells to derive a "condition-weighted area."

3. What are the key environmental and social drivers affecting resource extent and condition?

Land development, land management such as grazing and timber harvest practices, road traffic, exotic species, altered fire regimes, and regional climate change are all key drivers affecting the future of biodiversity in the region (Sierra Nevada Ecosystem Project 1996). For this exercise we focused on private lands, land development, and roads as key determinants of ecological condition on private lands in the region. The privately owned western foothills of the Sierra Nevada are among the most rapidly developing regions of the state. The habitat conversion and fragmentation associated with that development are a major conservation concern (Duane 1996, California State Department of Finance 1998). A more complete analysis would also consider threats and possible conservation responses associated with management designations and practices on private industrial forest lands and public lands in the region (Davis and Stoms 1996).

4. How are resource extent and condition likely to change in the future? 
We considered two scenarios of biodiversity change. The first scenario assumes that ecological condition on public lands and private reserves will be maintained and that ecological condition on nonreserved private lands will reach 0 by 2040 unless the site is protected. This is the conventional scenario used in reserve selection models in which only biodiversity in reserves contributes to meeting biodiversity conservation goals. The second scenario assumes that the condition on private nonreserved lands will decline only in areas that experience additional residential development and associated increases in the volume of local traffic on the existing road system. We used projections of future housing density developed by the California Department of Forestry and Fire Protection (Spero 2001). The choice of 2040 as a planning horizon was arbitrary. We could have as easily used any date in the future for which scenarios existed. Projections for 2000 and 2040 were based on population projections and historical patterns of residential development between 1950 and 1990. Future housing density was projected in $5 \times 5 \mathrm{~km}$ grid cells. For the purposes of estimating ecological impacts in the township quadrants, we assumed that the impact of houses was uniformly distributed across the grid cells and we interpolated to the township quadrants on an area-weighted basis. We used predicted housing density in 2000 in modeling current condition and predicted housing density in 2040 in modeling future condition. The difference between site condition in 2000 and 2040 was used to evaluate threat to RTE species, community types, and reserve buffers (Fig. 5).

5. What conservation tactics are available for different places and conservation concerns?

To reiterate, a conservation action is an investment to remove the threat to a particular resource. If the threat takes the form of land development, the conservation action could be land acquisition or the purchase of a conservation easement, and the cost would be the fee title cost or easement cost, respectively. To demonstrate the allocation model, we considered conservation of private lands by outright acquisition to remove the threat of development (see Machado et al.
2005 for an example based on conservation easements). Many, if not most, of Californial 's investments of public conservation funds take this form. This requires information on the geography of land values, which vary in fairly predictable patterns in response to social, spatial, and environmental factors.It was beyond the scope of our project to develop detailed land value information for California at the resolution of our planning units. For demonstration purposes only, we used 2002 data from the California Chapter of the American Society of Farm Managers and Rural Appraisers ( $\quad$ http://www.cala sfmra.com/landvalues/2002/index.html) for county-level estimates for land value of rangeland for several counties in the Sierra Nevada study area, and we estimated costs for the remaining counties that reflected the broad pattern of land use and development pressure relative to the known county values. The total conservation cost of a site is the product of the per hectare cost and the total area in hectares of land available for conservation in the site, i.e., private, unconverted land.

\section{Solution procedure}

Depending on the form of $U($.$) , its dependence on$ resource features of the sites, and the number of possible conservation actions $I$, this can be an extremely complex problem to solve optimally. This is a classic integer programming problem, and several heuristic algorithms are available to ease implementation of the model for large problems. Our formulation of $U($.) is fairly complicated and, as is common with most real-world conservation planning exercises, the number of sites ranges from thousands to tens of thousands. Even considering only fee-simple acquisition, the number of possible actions, $I$, can easily exceed $10^{9}$.

For the demonstration below we use a stepwise heuristic with updating. We mimic with this approach a series of sequential myopic conservation decisions. In the first stage, we choose the conservation action of the I possibilities that yields the greatest utility per conservation dollar. Following that conservation action, all resources and values are recalculated, and the procedure is repeated to identify the next conservation action. The whole process is repeated until the budget has been spent. This approach amounts to acting, at any 
Fig. 5. Modeled threat to California terrestrial biodiversity based on predicted changes in ecological condition because of housing development that would occur between 2000 and 2040 in the absence of conservation interventions. Grid resolution is 1 ha.

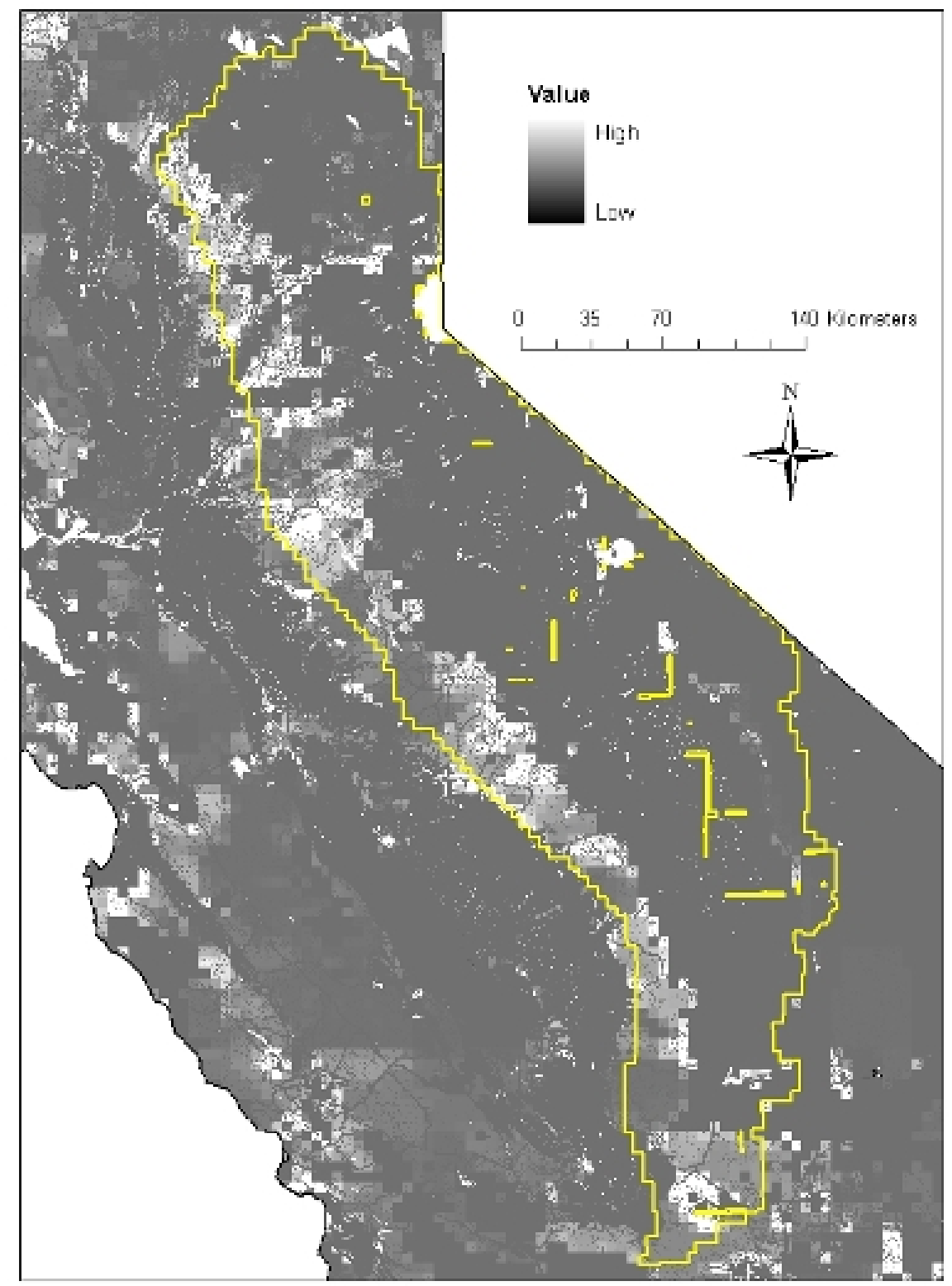


decision point, on the conservation alternative that yields the highest marginal utility per dollar. This is a version of the "greedy algorithm" with updating in integer programming. Target-based search methods such as simulated annealing or genetic algorithms are likely to achieve better results because they consider whole sets as possible solutions rather than iteratively selecting conservation actions (Possingham et al. 2000). We are currently examining their application to this problem.

On the other hand, in practice resource managers and decision makers often revert to a stepwise decision-making approach that reflects the reality that they must continually update information and reassess priorities rather than committing inflexibly to a specific portfolio and pursuing that portfolio through time. Although there is an emerging literature that lends theoretical justification to a stepwise approach under uncertainty (Costello and Polasky 2004, Meir et al. 2004), we would ideally like to solve our problem optimally and, in the spirit of the integer programming literature, compare the performance of several heuristic algorithms. However, that comparative analysis is not the focus of this paper.

Using this approach, what are the highest-priority areas for investing today's limited conservation funds? We calculated a marginal conservation utility for each objective at each site as well as a multicriteria score, i.e., the weighted sum of objective scores. Site conservation cost was estimated, and the final site score was estimated as the ratio of composite utility or the equal weighting on the three objectives divided by cost. We then applied the greedy selection algorithm with a fixed budget and a constraint of least 400 ha of available land in the site to identify a hypothetical regional conservation portfolio. We carried out the selection process for the first 50 sites as an arbitrary stopping point corresponding to a total fixed budget of $\$ 144$ $x 10^{6}$. In practice, a planner might apply an annual budget or a budget associated with a particular multiyear program, updating priorities over time as land use changes in the planning region.

The prototype algorithm took approximately $2 \mathrm{~h}$ to complete the selection on a standard desktop computer, but undoubtedly this could be significantly accelerated with better software engineering.

\section{RESULTS}

\section{Site scores for hotspots of rare, threatened, and endangered species}

Because most special-status species are already considered globally threatened, we have made the simplifying assumptions that all individual occurrences on unprotected lands are threatened and that the highest priority should be given to protecting the sites that are currently in the best condition. In this example, we have set the same goal for all species, i.e., protect all known occurrences, but species-specific goals could also be applied to give greater weight to some species. For every listed plant or animal species, the condition-weighted area of unprotected land in every site in which the species has been recorded is summed to calculate the pool of available conservation land for that species. Each site contributes a fraction of the total pool for each species. For each site, fractional contributions are summed over all species. A site has higher conservation value for rare, threatened, and endangered (RTE) species if unprotected land in the site accounts for a large fraction of the total rangewide condition-weighted unprotected area for each of a relatively large number of RTE species.

Scores for township quadrants in the Sierra Nevada bioregion range from 0 to 0.98 (Fig. 6). Because most special-status species in the Sierra Nevada are localized plant taxa, scores are largely dictated by plant species, and a very different pattern results if only animal species are considered (Davis et al. 2003). Clusters of high-scoring sites are scattered across the private lands of the western foothills. Many of the high-scoring sites are areas with distinctive soils and associated concentrations of rare plant species. For example, the highest-scoring cells in the foothills of Nevada, Placer, Amador, and El Dorado Counties are locations of serpentine and gabbroic soils that support chaparral communities with rare endemic plant species. Similarly, several high-scoring sites at the southern end of the region are areas of Blue oak (Quercus douglasii) woodlands on adobe soils that support rare plant species. 
Fig. 6. Site marginal utility as a hotspot of rare, threatened, or endangered species. Highest-scoring sites are dark blue. County boundaries are drawn, and existing public and private reserved lands are shown as a gray mask.

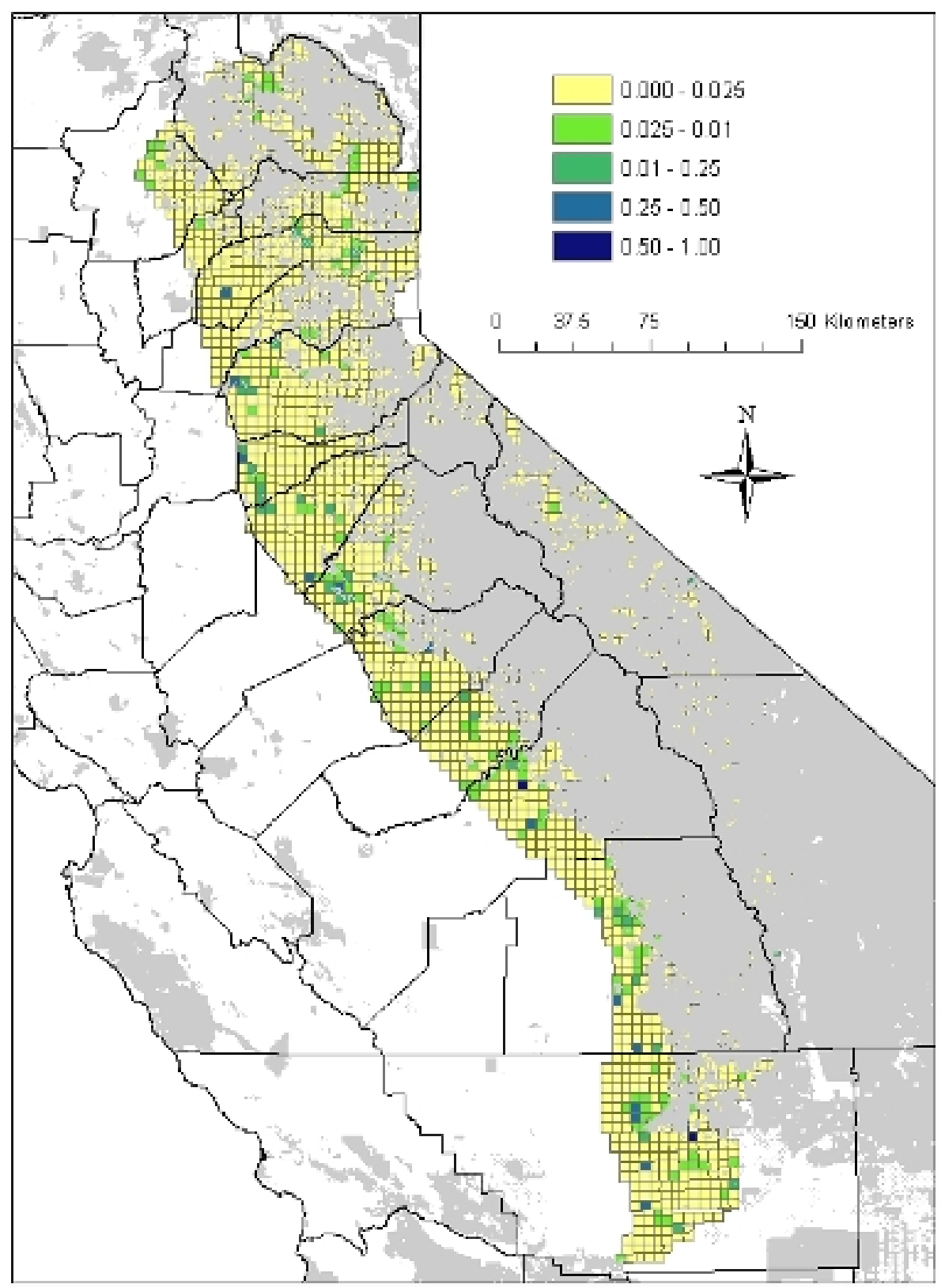


Fig. 7. Site marginal utility scores for representing wildlife habitat types, assuming that in 2040 unprotected lands will not contribute to habitat representation. County boundaries are drawn, and existing public and private reserved lands are shown as a gray mask.

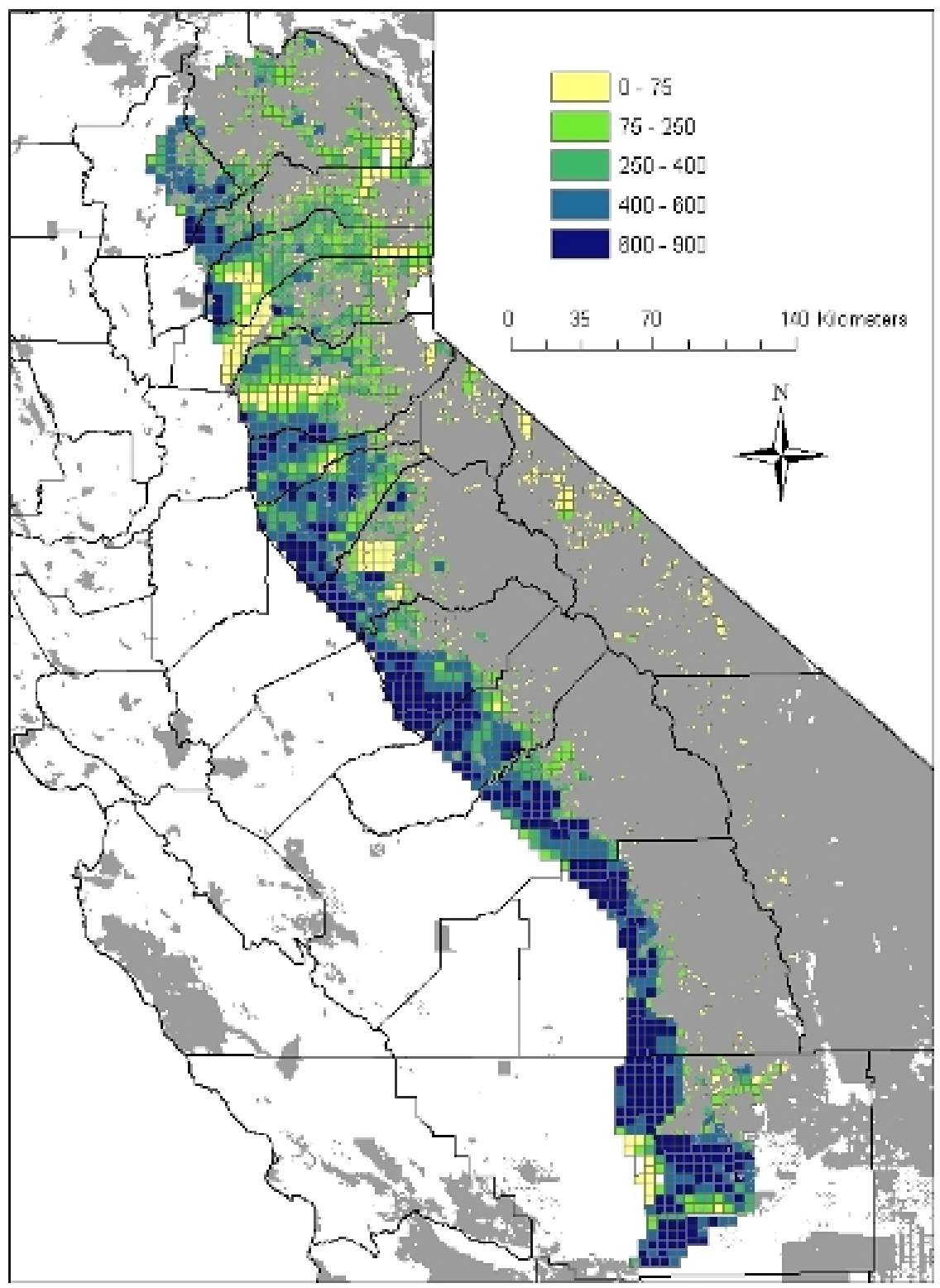




\section{Site scores for under-represented wildlife habitat types}

Under the simplest scenario that no biodiversity will be retained on unprotected private lands, the highest site scores occured over large areas of the privately owned foothills of the southern Sierra Nevada and Tehachapi ranges in which the habitat types with lowest protection, e.g., blue oak (Quercus douglasii)-foothill pine (Pinus sabiniana) and valley oak (Quercus lobata) woodlands, are both widespread and currently in good condition (Fig. 7).

Under the California Department of Forestry and Fire Protection scenario of projected housing development in the region, the high-scoring sites are clustered in foothill environments that support under-represented habitat types in relatively good condition and in which rural housing density has increased in recent decades and is projected to continue increasing in the future. This includes western foothill and lower montane areas such as Eldorado, Calaveras, and Madera counties (Fig. 8). Rank correlation among site scores under the contrasting scenarios is very low. For example, only three sites occur in the top 200 sites in both scenarios. This is because, in general, the more threatened sites are in poorer condition, e.g., they exhibit higher road densities and higher rural residential housing densities, than less threatened, unprotected sites.

\section{Sites for expanding small reserves}

Public lands in the southern Sierra Nevada are mainly in large continuous holdings at mid-to-high elevations such as Sequoia-King's Canyon National Park and the Inyo and Sierra national forests. In contrast, there are no national parks in the northern Sierra Nevada, and large areas of national forests are fragmented into a checkerboard pattern of alternating sections of public and private lands. For this reason, clusters of high conservation values are located in the northern foothills in which public lands tend to be in small isolated units and private lands are in relatively good condition now, although the growth model predicts increased development over the next 40 yr (Fig. 9).

\section{Composite utility and marginal conservation value}

The correlation between site scores for RTE species and under-represented habitat types or reserve buffers is low, 0.08 and 0.05 , respectively, whereas the correlation between scores for habitat types and reserve buffers is a moderate 0.62 . Thus, few sites have high composite utility, and many sites have intermediate scores because they score high in one or two criteria (Fig. 10). Given this result, site cost figures prominently in a site's marginal conservation value.

\section{A hypothetical conservation portfolio}

The 50 selected sites are widely dispersed along the western foothills of the planning region, with a few isolated sites on the eastern side of the Sierra Nevada (Fig. 11). This portfolio contains approximately 74,000 ha of available private land at a predicted total acquisition cost of $\$ 144 \times 10^{6}$, an average cost of $\$ 1940 /$ ha or slightly above the average land price in the region. These 50 sites would protect roughly $24 \%$ of the starting composite utility in the bioregion on $4 \%$ of the remaining available land. This conservation scenario should be interpreted as one possible alternative based on an equal weighting of conservation objectives, our estimates of land values, the choice of reference regions and goals, and one particular scenario of future land development.

Forty of the 50 sites contributed positively to all three objectives. The sites with the highest values for RTE species and reserve expansion objectives were included in the final portfolio, and the portfolio site with the highest value for the representation objective was relatively close to the maximum value in the region. The site with the highest initial composite utility was selected fifth because its estimated cost lowered its relative marginal value.

\section{DISCUSSION}

Integrated conservation planning frameworks are especially important given the trend toward shifting from a top-down command-and-control planning style to more collaborative processes (Klosterman 1997). Conservation usually raises conflicts between competing ideological and/or economic 
Fig. 8. Site marginal utility scores for representing wildlife habitat types, accounting for projected patterns of housing development in the region and assuming that unprotected lands can still contribute to biodiversity protection (cf. Fig. 7). County boundaries are drawn, and existing public and private reserved lands are shown as a gray mask.

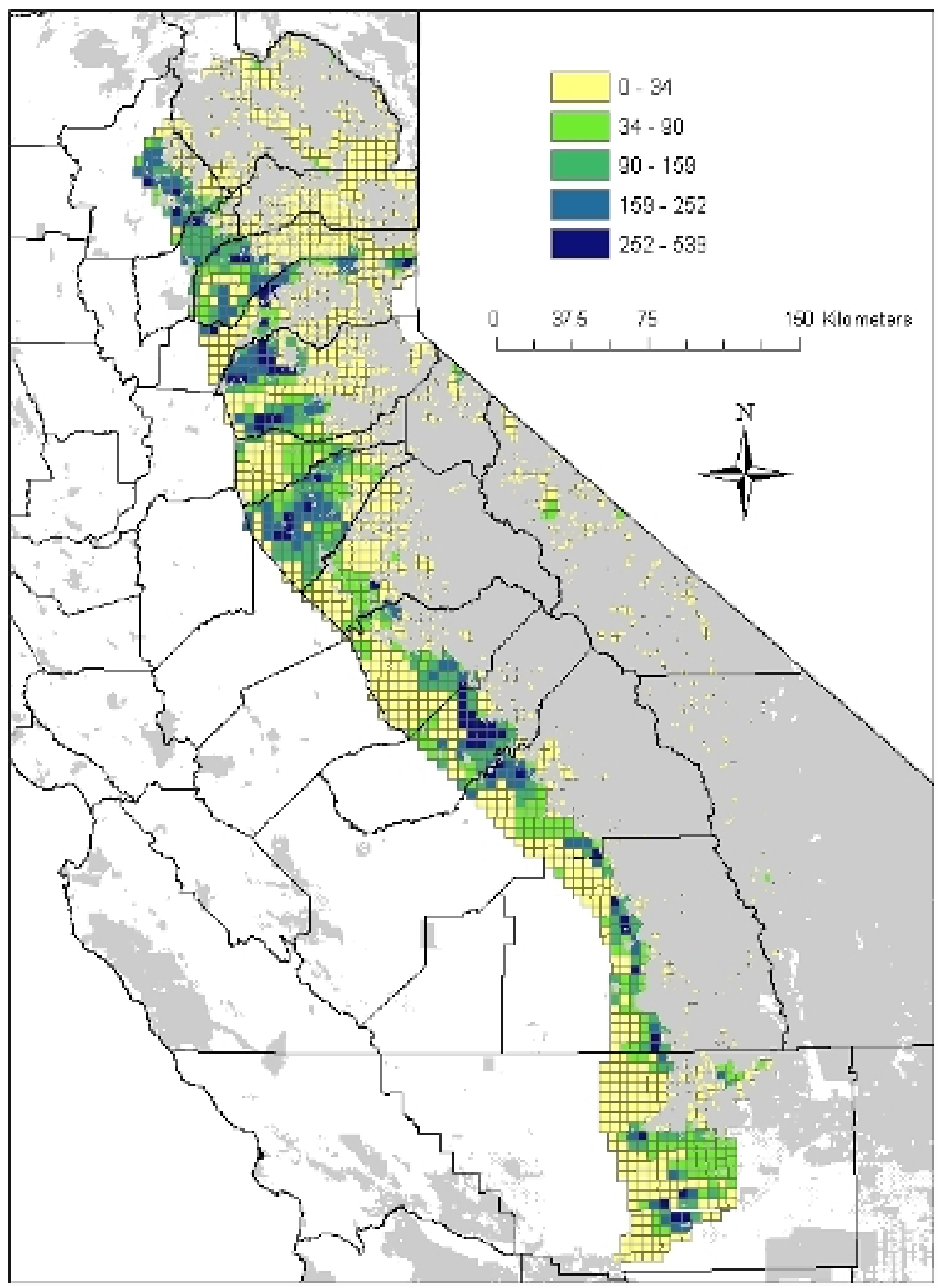


Fig. 9. Site marginal utility scores for expanding existing reserves. County boundaries are drawn, and existing public and private reserved lands are shown as a gray mask.

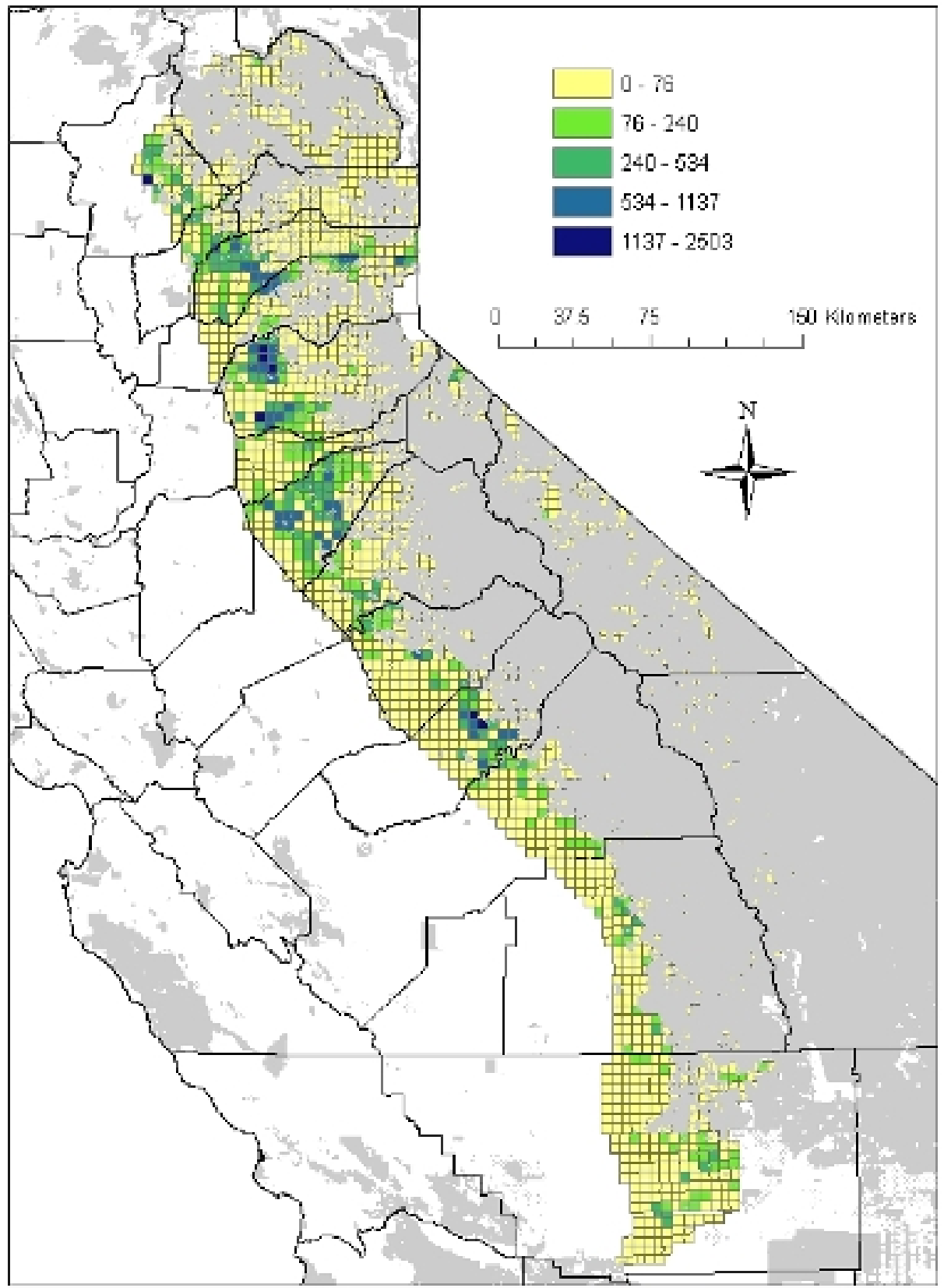


Fig. 10. Composite site scores derived by summing the scores for three conservation criteria (Figures 6, 8, and 9). Criteria were weighted equally in this example.

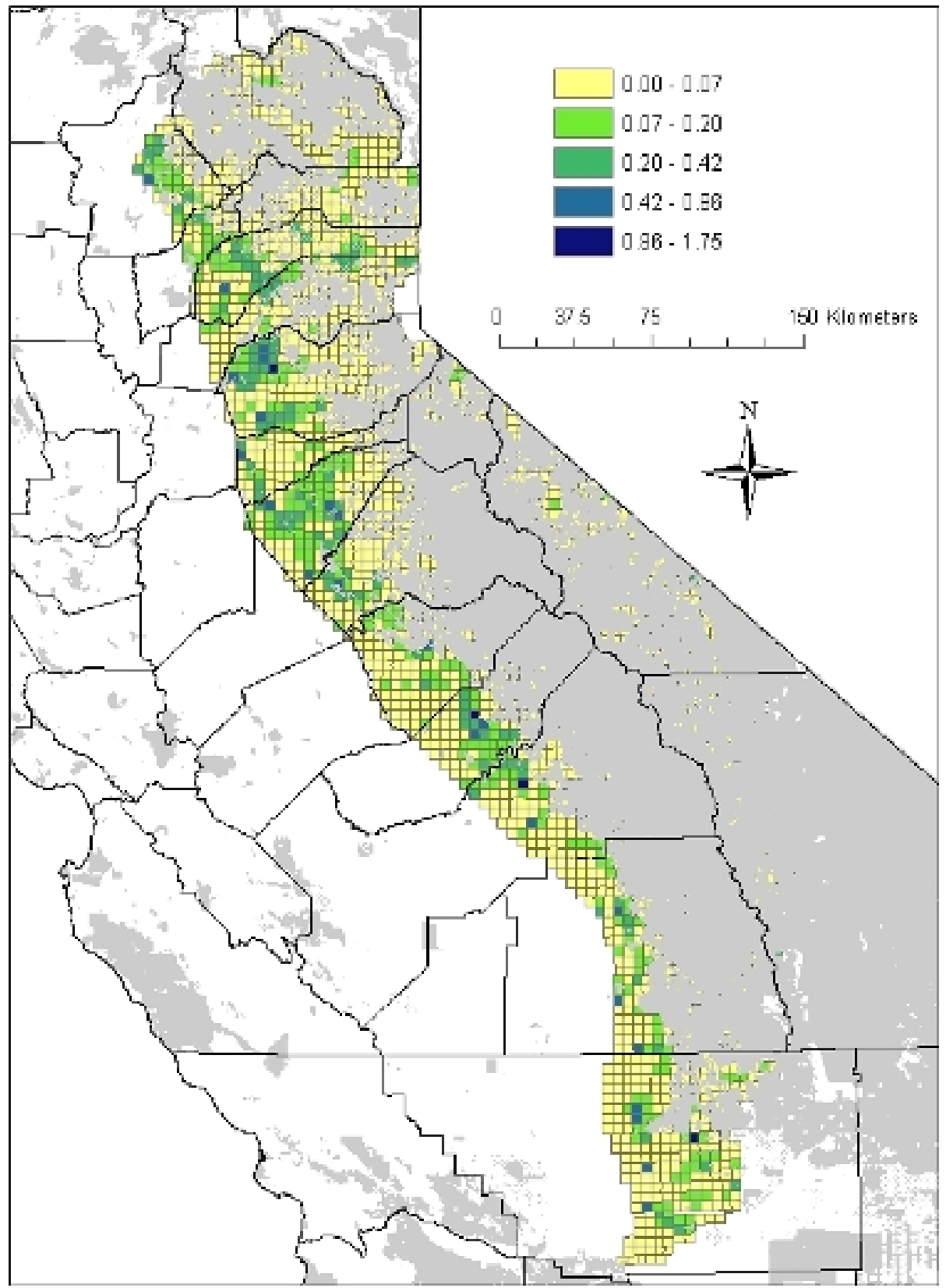


Fig. 11. A portfolio of 50 sites selected by the greedy algorithm and a budget of $\$ 144$ million. The color indicates the order of site selection with sites 41-50 being the last 10 selected. County boundaries are drawn, and existing public and private reserved lands are shown as a gray mask.

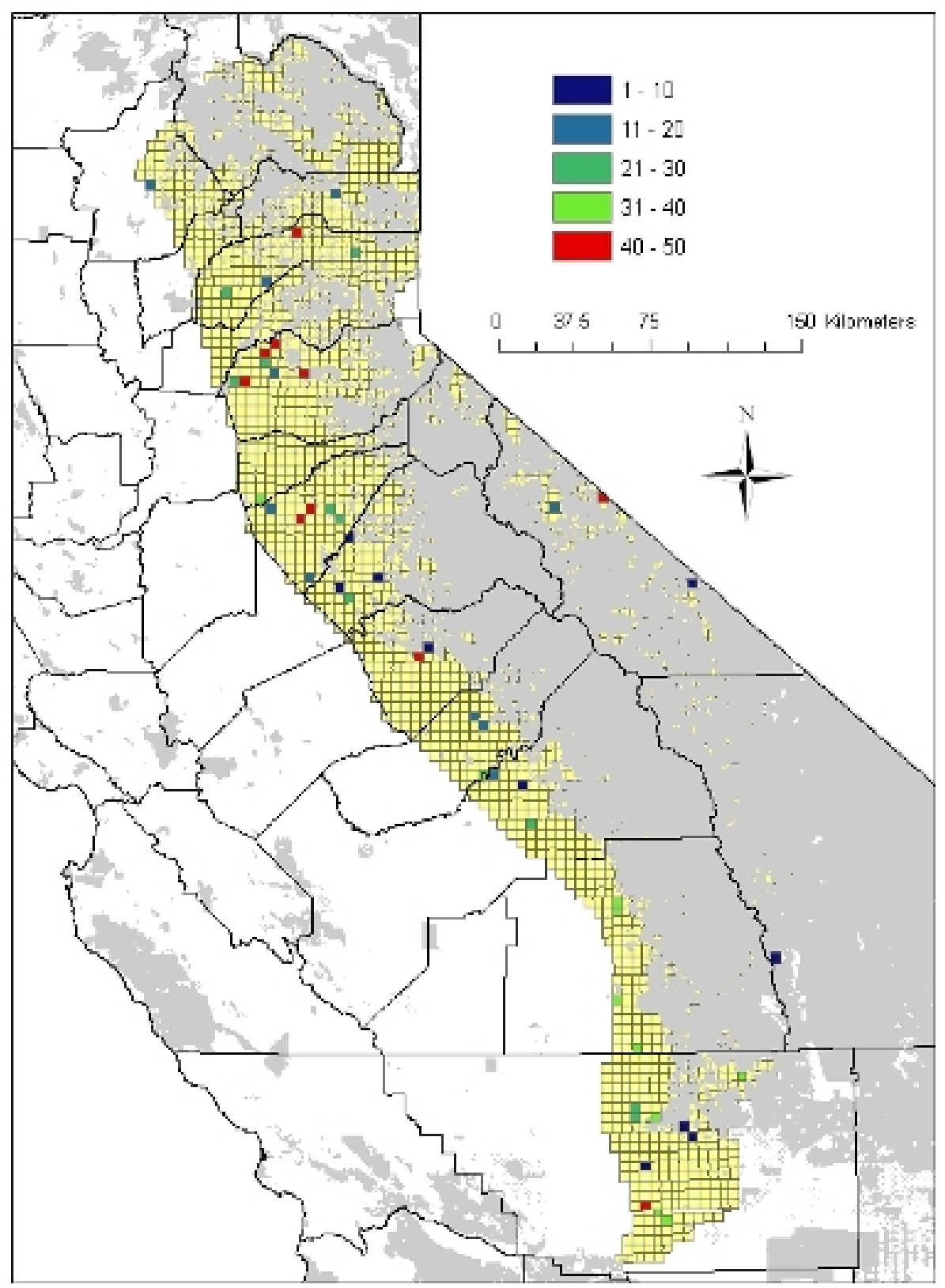


interests, and success may depend on achieving political agreement through informed negotiation (Pressey et al. 1995). Well-designed conservation planning frameworks have value in such negotiations because they help stakeholders articulate more explicit goals, promote better understanding of natural resource amenities and the threats to those amenities, and facilitate the production and evaluation of alternative policy and management scenarios. Furthermore, because systematic conservation planning involves gathering, organizing, and maintaining information on the condition and conservation status of resources across the planning region, integrated frameworks facilitate ongoing "auditing" of conservation efforts and assessment of conservation program effectiveness (Margules and Pressey 2000).

Four concepts have had a strong influence on the development of alternative frameworks of conservation planning: complementarity, efficiency, irreplaceability, and retention. Readers may wonder how our measure of conservation value relates to these established concepts. Are we rejecting them, extending them, or simply using nontraditional terminology?

Complementarity is a measure of the extent to which a nonreserve area, or set of areas, could contribute unrepresented features to a reserve system (Margules and Pressey 2000). Almost all conservation planning tools use complementarity to select sites efficiently. Conservation networks can be assembled more rapidly when all the sites have high complementarity. In this sense, complementarity is a special type of marginal utility function, i.e., it measures the contribution toward a set of goals from the current starting point. We refine the measure of complementarity by considering the threat to a site's ecological condition and by introducing a flexible utility function. Previous applications have assumed a step function with full utility for every unit of a feature until the goal is achieved, at which point the marginal utility becomes zero. Ferrier et al. (2000) implicitly adopted a diminishing marginal utility approach by applying a weight that was a function of the proportion of the goal currently met. The final difference from the traditional use of complementarity is that our goals are stated relative to the extent to which a feature persists in the landscape rather than the amount receiving formal protection. The purpose of complementarity is to achieve efficiency, the second concept, by accomplishing the greatest possible amount of conservation within a set number of sites (Pressey et al. 2004). Our modifications to strict complementarity provide a more direct measure of cost-effectiveness than do conventional measures of efficiency.

A third important concept in conservation planning is irreplaceability (Pressey et al. 1994). This represents the likelihood that a site will be required to achieve conservation goals. A fully irreplaceable site is one that is home to one or more unique biodiversity features. Like complementarity, irreplaceability is a function of the extent of the feature at a site with respect to distance from the conservation goal; how much of the feature exists in the region relative to the goal is also considered. The irreplaceability of a feature will be high if the goal for the feature is a large proportion of the total amount, i.e., the width of area under the marginal utility curve in Fig. 2. The marginal value framework does not explicitly calculate irreplaceability. However, it does normalize the sum of site utility by the total regional utility, and thus is based on logic similar to that used to determine irreplaceability.

Rather than using the fourth concept, retention, to indicate how much of a feature has been preserved, Pressey et al. (2004) define it as the "area compromised" to the extent that targets could not be achieved based on the amount of the feature that remains. Thus, it considers whether future management will be compatible with the retention of the feature so that conservation can be focused on features whose targets will not be met without intervention. Our framework was explicitly designed to increase retention by quantifying expected loss of biodiversity from land-use change.

\section{Beyond reserves}

By setting conservation priorities based on threat to current condition, we depart from the conventional reserve-based view of conservation networks. Instead of presuming that nonreserved lands make no contribution to regional resource levels, we expect these lands to contribute in a way that depends on their current ecological condition. Similarly, we expect future contributions to depend on future condition. For the Sierra Nevada case study, which focused on terrestrial biodiversity, we derived a simple condition measure based on land use, housing density, road networks, and current 
forest structure. Ideally, we would have used more sophisticated process-based measures. These become more feasible at local scales for which more detailed information is available. We could have also done more detailed accounting of current and future conditions on public lands, and this may have changed public investment priorities on private nonprotected lands. The key point is that the formulation is general enough to accommodate a range of management regimes without imposing a simple reserved/nonreserved dichotomy (Wallington et al. 2005).

\section{Lessons from the Sierra Nevada case study}

We chose the Sierra Nevada bioregion as a case study because of its biological and economic significance and because we were familiar with the region from spending many years in conservation planning activities in the area. Based on that familiarity, we are encouraged by the model's performance using existing data. Patterns of scores for the different objectives are sensible and interpretable in the light of our current understanding of biological and social patterns and trends in the region.

Our spatial analytical design involves a planning region, i.e., the set of candidate sites for investments; criterion-specific reference regions for measuring site conservation values; conservation sites; and observations within sites. Based on extensive deliberations with agency representatives, we used irregular township quadrants because of their size, alignment with existing land-ownership lines, and relatively uniform shape. However, the framework could as readily be applied to either irregular polygons or regular grids.

Selecting the appropriate scale or set of scales for description and analysis is one of the most important and difficult decisions at the outset of any conservation planning process. As discussed by Austin and Margules (1986) and demonstrated in a number of empirical analyses (e.g., Stoms 1994, Pressey and Logan 1998), the choice of planning units for conservation planning is critically important in determining the measured conservation value of any location and the distribution and extent of the conservation solution. There is no flawless system of planning units for conservation assessments and analysis: scale dependence and uncertainty will be intrinsic properties of any system of spatial assessment units.
Our design is similar to the hierarchical constructs used in other systematic conservation planning efforts except that we also introduce the concept of the "reference region." We find this especially useful in a multicriterion framework in which the marginal utility associated with conserving a site is assessed relative to different sets of sites within the planning region. For example, a site's values for, e. g., species protection relative to the species' range and watershed conservation relative to the watershed or the achievement of bioregional habitat representation goals, can be determined at the same time. Keeping track of multiple reference regions is more complicated, but in our experience the results are worth the added effort.

In the Sierra Nevada case study, scores for rare, threatened, and endangered (RTE) species are driven by the region's diverse and endemic flora and are highest in privately owned areas with distinctive edaphic conditions and associated restricted plant associations. As is so often the case, the survey data are spotty, most of the conservation value resides in a few areas with high irreplaceability, the pattern can be very different for taxonomic groups, and the scores have only a low correlation with those for other conservation objectives (e.g., Kershaw et al. 1995, Lombard et al. 1999, Noss et al. 2002).

Spatial considerations of reserve size, shape, and connectivity figure prominently in modern conservation planning and decision making, and the identification of approaches for optimal spatial design is an active area of research. Current approaches range from relatively simple algorithms that can be used to promote the selection of contiguous sites (McDonnell et al. 2002) to models that locate habitat patches of adequate size and connectivity based on species-specific habitat requirements (Calkin et al. 2002, Santelmann et al. 2004). Our approach to spatial design falls into the former category as a relatively simple algorithm that can be implemented over a large number of sites. Incorporating the species-area power law provides a means of awarding diminishing value to larger contiguous areas. The approach appears to work well, although it needs additional testing. In the Sierra Nevada case study, high-scoring areas in the "checkerboard" of public and private lands west of Lake Tahoe combine highly fragmented public lands with areas under considerable pressure for rural residential and recreational development. Groups such as the Trust for Public Land are actively 
working with the U.S. Forest Service and private timber companies to consider conservation alternatives for these lands.

The difference between site scores for representing habitat types with or without accounting for the threat of development highlights several nowfamiliar issues in conservation planning. First, unless ecological condition or threat is taken into consideration, sites supporting widespread habitat types tend to have low irreplaceability depending on how finely the habitat types are distinguished in the classification and mapping system (Pressey and Logan 1995, Davis et al. 1996). This means that site prioritization will be driven by other considerations and objectives such as RTE species or the scaledependent habitat richness of the sites. Second, and of more immediate relevance to our model, site scores for habitat representation can change dramatically when threats and site costs are considered. Conservation decision makers constantly confront the dilemma of whether to act in areas that are immediately threatened but in which conservation actions are accordingly more expensive or to opt for projects in which threats are less imminent but the cost of land is also lower. In practice, conservation funds in California are often invested reactively. Therefore, conservation priorities are extremely sensitive to scenarios of threat. Systematic conservation planning must find ways to bring scenarios of threat formally into decision support models (Costello and Polasky 2004). Our model offers one way to do this that readily accommodates the common planning practice of considering several alternative scenarios of land development.

Finally, conservation costs can vary greatly across a region, and in the case of the Sierra Nevada bioregion they can vary as much as the mapped variation in resource quality or threat. Accounting for cost in a cost-effectiveness framework can change the view of priorities, sometimes in surprising ways. Therefore it is important to use highly resolved data on the variation in land prices. The county-level averages used in our example undoubtedly fail to capture much of that variation related to distance from urban areas and roads, slope, zoning, and other factors.

\section{Model strengths and limitations}

Because the California Legacy Project was terminated after $3 \mathrm{yr}$, the approach for it that we developed was never fully vetted with the relevant state agencies or other stakeholder groups, and it remains to be seen whether the ideas and methods presented here will prove useful in real planning efforts. The specific conservation criteria and the methods used to measure ecological condition received considerable discussion and input from agency personnel and academic scientists, but the maps have not been field tested and suffer from many known and presumably unknown uncertainties and biases. The metrics and data sources are described in detail elsewhere (Davis et al. 2003), and we welcome review and feedback. However, we have not focused on the details of our specific criteria and data here because we want to emphasize that our model formulation can be readily adapted to alternative criteria and data sources. The strengths of the framework here are generality, explicitness, flexibility for exploring alternative goals and objectives, consideration of threats and costs as well as biodiversity values, and the use of a formal costeffectiveness analysis for comparing alternative conservation actions. We believe that this framework can be applied to various conservation problems, such as public land planning, assigning priorities for restoration, or assessing the conservation value of a set of currently available properties.

This data-driven framework depends on consistent information across the planning area, but this does not preclude the incorporation of expert knowledge and local information. Judgment is involved at many stages, including goal setting, choosing conservation criteria and criterion weights, developing alternative scenarios, shaping utility functions, reviewing and revising site-level input data, and interpreting model results. We envision an incremental planning process that involves iteration and refinement at multiple scales of analysis (Steinitz 1990).

The framework as currently implemented is somewhat cumbersome and needs a simple user interface and software to facilitate participatory analysis and planning. We are currently developing such a planning support environment in collaboration with NatureServe (http://www.nature serve.org/prodServices/vista.jsp). After developing this software it will be much easier to conduct sensitivity analyses on models of development threat, different planning horizons, classification schemes, and parameters and marginal utility functions that are integral to estimating site 
conservation value. This is a generic problem for conservation planners and collaborative processes: the number of choice points needed to arrive at a conservation value for a site or identify a reserve network portfolio is usually very large. By adding utility curves, threat, and cost to the analysis, we have more completely specified the problem but have also added even more parameters and options to a list that is already intimidating.

The framework described here is useful in helping the analyst understand the current spatial relationships of conservation values, threats, and costs and in setting priorities. However, it does not consider the effect that taking conservation actions will have on the ensuing distribution of development threat or how conservation actions could reverberate through land markets. Conservation does not quench the demand for new housing or other economic activities; rather, it displaces that demand to another area in a way that depends intrinsically on the geography of conservation decisions. Establishment of new reserves will likely affect local land prices as the properties adjacent to the reserve gain in value and as the demand for housing in more remote areas increases (Newburn et al.2005). We are now looking into ways to update the threat and cost surfaces as part of updating our calculations of conservation value. This will be especially important for applications of the framework at finer spatial scales.

Responses to this article can be read online at:

http://www.ecologyandsociety.org/voll1/iss 1/art33/responses/

\section{Acknowledgments:}

We gratefully acknowledge the financial and logistical support of The Resources Agency of California and the National Center for Ecological Analysis and Synthesis, a center funded by the National Science Foundation (Grant \#DEB-0072909), the University of California, and the Santa Barbara campus. Additional funding was provided by USDA National Research Initiative Rural Development Grant \#005-35401-15320. We thank former Secretary of Resources Mary Nichols, former California Legacy Project Director Madelyn Glickfeld, former Resources Agency Science Advisor Greg Greenwood, California Fish and
Game Senior Biologist Marc Hoshovsky, and Bill Stewart, Chief of the CDF Fire and Resource Assessment Program, for their guidance and advice throughout the project. Thanks also to California Legacy Project staff members Rainer Hoenicke and Mike Byrne for their collaboration and technical support. This work benefited from the significant intellectual contributions of many National Center for Ecological Analysis and Synthesis working group participants and research assistants, especially Elia Machado, Josh Metz, Ross Gerrard, Sandy Andelman, Helen Regan, Richard Church, Hugh Possingham, and Miguel Araújo.

\section{LITERATURE CITED}

Ando, A., J. Camm, S. Polasky, and A. Solow. 1998. Species distributions, land values, and efficient conservation. Science 279:2126-2128.

Austin, M. P., and C. R. Margules. 1986. Assessing representativeness. Pages 45-67 in M. B. Usher, editor. Wildlife conservation evaluation. Chapman and Hall, London, UK.

Belbin, L. 1993. Environmental representativenes: regional partitioning and reserve selection. Biological Conservation 66:223-230.

Benton, T. G., J. A. Vickery, and J. D. Wilson. 2003. Farmland biodiversity: Is habitat heterogeneity the key? Trends in Ecology \& Evolution 18 (4):182-188.

Cabeza, M., and A. Moilanen. 2001. Design of reserve networks and the persistence of biodiversity. Trends in Ecology \& Evolution 16:242-248.

California State Department of Finance. 1998. County population projections with age, sex and racelethnic detail: July, 1990-2040 in 10-year increments. Demographic Research Unit, California State Department of Finance, Sacramento, California, USA.

California Legislative Analyst's Office. 1996. LAO analysis of the 1996-97 budget bill resources, part I. California Legislative Analyst's Office, 
Sacramento, California, USA.

Calkin, D. E., C. A. Montgomery, N. H. Schumaker, S. Polasky, J. L. Arthur, and D. J. Nalle. 2002. Developing a production possibility set of wildlife species persistence and timber harvest value. Canadian Journal of Forest Research 32:1329-1342.

Church, R. L., D. M. Stoms, and F. W. Davis. 1996. Reserve selection as a maximal covering location problem. Biological Conservation 76:105-112.

Cocks, K. D., and I. A. Baird. 1989. Using mathematical-programming to address the multiple reserve selection problem: an example from the Eyre Peninsula, South Australia. Biological Conservation 49:113-130

Costello, C., and S. Polasky. 2004. Dynamic reserve site selection. Resource and Energy Economics 26:157-174.

Cowling, R. M., and R. L. Pressey. 2001. Rapid plant diversification: planning for an evolutionary future. Proceedings of the National Academy of Sciences of the United States of America 98:5452-5457.

Cowling, R. M., R. L. Pressey, M. Rouget, and A. T. Lombard. 2003. A conservation plan for a global biodiversity hotspot: the Cape Floristic region, South Africa. Biological Conservation 112:191-216.

Davis, F. W., and D. M. Stoms. 1996. Sierran vegetation: a gap analysis. Pages 25-1-25-19 in Sierra Nevada Ecosystem Project: final report to Congress. Volume II. Assessments and scientific basis for management options. Centers for Water and Wildland Resources, University of California, Davis, California, USA.

Davis, F. W., D. M. Stoms, R. L. Church, B. J. Okin, and K. N. Johnson. 1996. Selecting biodiversity management areas. Pages 26-1-26-18 in Sierra Nevada Ecosystem Project: final report to Congress. Volume II. Assessments and scientific basis for management options. Centers for Water and Wildland Resources, University of California, Davis, California, USA.

Davis, F. W., D. M. Stoms, C. Costello, E. Machado, J. Metz, R. Gerrard, S. Andelman, H. Regan, and R. Church. 2003. A framework for setting land conservation priorities using multicriteria scoring and an optimal fund allocation strategy. National Center for Ecological Analysis and Synthesis, University of California, Santa Barbara, California, USA. Available online at: http ://www.biogeog.ucsb.edu/pubs/Technical\%20Reports/ TerrBiod framework-report.pdf.

Dobson, A. P., J. P. Rodriguez, W. M. Roberts, and D. S. Wilcove. 1997. Geographic distribution of endangered species in the United States. Science 275:550-553.

Duane, T. P. 1996. Human settlement, 1850-2040. Pages 235-360 in Sierra Nevada Ecosystem Project: final report to Congress. Volume II. Assessments and scientific basis for management options. Centers for Water and Wildland Resources, University of California, Davis, California, USA.

Faith, D. P., P. A. Walker, and C. R. Margules. 2001. Some future prospects for systematic biodiversity planning in Papua New Guinea and for biodiversity planning in general. Pacific Conservation Biology 6:325-343.

Ferrier, S., R. L. Pressey, and T. W. Barrett. 2000. A new predictor of the irreplaceability of areas for achieving a conservation goal, its application to real-world planning, and a research agenda for further refinement. Biological Conservation 93:303-325.

Forman, R. T. T., and S. K. Collinge. 1996. The "spatial solution" to conserving biodiversity in landscapes and regions. Pages 537-568 in R. M. DeGraaf and R. I. Miller, editors. Conservation and faunal diversity in forested landscapes. Chapman Hall, New York, New York, USA.

Forman, R. T. T., and R. D. Deblinger. 2000. The ecological road-effect zone of a Massachusetts (USA) suburban highway. Conservation Biology 14:36-46.

Germaine, S. S., S. S. Rosenstock, R. E. Schweinsburg, and W. S. Richardson. 1998. Relationships among breeding birds, habitat, and residential development in Greater Tucson, Arizona. Ecological Applications 8:680-691.

Guikema, S., and M. Milke. 1999. Quantitative decision tools for conservation programme planning: practice, theory and potential. Environmental 
Conservation 26:179-189.

Hughey, K. F. D., R. Cullen, and E. Moran. 2003. Integrating economics into priority setting and evaluation in conservation management. Conservation Biology 17:93-103.

Hyman, J. B., and S. G. Leibowitz. 2001. JSEM: a framework for identifying and evaluating indicators. Environmental Monitoring and Assessment 66: $207-232$.

Keisler, J. M., and R. C. Sundell. 1997. Combining multi-attribute utility and geographic information for boundary decisions: an application to park planning. Journal of Geographic Information and Decision Analysis 1:100-119.

Kershaw, M., G. M. Mace, and P. H. Williams. 1995. Threatened status, rarity, and diversity as alternative selection measures for protected areas: a test using Afrotropical antelopes. Conservation Biology 9:324-334.

Klosterman, R. E. 1997. Planning support systems: a new perspective on computer-aided planning. Journal of Planning Education and Research 17:45-54.

Lombard, A. T., C. Hilton-Taylor, A. G. Rebelo, R. L. Pressey, and R. M. Cowling. 1999. Reserve selection in the Succulent Karoo, South Africa: coping with high compositional turnover. Plant Ecology 142:35-55.

Machado, E. A. , D. M. Stoms, F. W. Davis, and J. Kreitler. 2006. Prioritizing farmland preservation cost-effectively for multiple objectives. Journal of Soil and Water Conservation 61, in press.

Malczewski, J. 2000. On the use of weighted linear combination method in GIS: common and best practice approaches. Transactions in GIS 4:5-22.

Margules, C. R., and R. L. Pressey. 2000. Systematic conservation planning. Nature 405:243-253.

Mayer, K.E., and W.F. Laudenslayer, Jr. 1988. A guide to the wildlife habitats of California. California Department of Forestry and Fire Protection, Sacramento, California, USA.

McDonnell, M. D., H. P. Possingham, I. R. Ball, and E. A. Cousins. 2002. Mathematical methods for spatially cohesive reserve design. Environmental Modeling \& Assessment 7:107-114.

McHarg, I. L. 1969. Design with nature. Doubleday, Garden City, New York, USA.

Meir, E., S. Andelman, and H. P. Possingham. 2004. Does conservation planning matter in a dynamic and uncertain world. Ecology Letters 7:215-224.

Metrick, A., and M. L. Weitzman. 1998. Conflicts and choices in biodiversity preservation. Journal of Economic Perspectives 12:21-34.

Newburn, D., S. Reed, P. Berck, and A. Merenlender. 2005. Economics and land-use change in prioritizing private land conservation. Conservation Biology 19:1411-1420.

Noss, R. F. 2000. Maintaining the ecological integrity of landscapes and ecoregions. Pages 191-208 in D. Pimentel, L. Westra, and R. F. Noss, editors. Ecological integrity: integrating environment, conservation, and health. Island Press, Washington, D.C., USA.

Noss, R. F., C. Carroll, K. Vance-Borland, and G. Wuerthner. 2002. A multicriteria assessment of the irreplaceability and vulnerability of sites in the Greater Yellowstone Ecosystem. Conservation Biology 16:895-908.

Possingham, H., I. Ball, and S. Andelman. 2000. Mathematical methods for identifying representative networks. Pages 291-305 in S. Ferson and M. Burgman, editors. Quantitative methods for conservation biology. Springer-Verlag, New York, New York, USA.

Prendergast, J. R., R. M. Quinn, and J. H. Lawton. 1999. The gaps between theory and practice in selecting nature reserves. Conservation Biology 13:484-492.

Pressey, R. L., S. Ferrier, C. D. Hutchinson, D. P. Sivertsen, and G. Manion. 1995. Planning for negotiation: using an interactive geographic information system to explore alternative protected area networks. Pages 23-33 in D. A. Saunders, J. L. Craig, and E. M. Mattiske, editors. Nature conservation: the role of networks. Surrey Beatty, Sydney, Australia. 
Pressey, R. L., C. J. Humphries, C. R. Margules, R. I. Vane-Wright, and P. H. Williams. 1993. Beyond opportunism: key principles for systematic reserve selection. Trends in Ecology and Evolution 8:124-128.

Pressey, R. L., I. R. Johnson, and P. D. Wilson. 1994. Shades of irreplaceability: towards a measure of the contribution of sites to a reservation goal. Biodiversity and Conservation 3:242-262.

Pressey, R. L., and V. S. Logan. 1995. Reserve coverage and requirements in relation to partitioning and generalization of land classes: analyses for western New South Wales. Conservation Biology 9:1506-1517.

Pressey, R. L., and V. S. Logan. 1998. Size of selection units for future reserves and its influence on actual versus targeted representation of features: a case study in western New South Wales. Biological Conservation 85:305-319.

Pressey, R. L., M. E. Watts, and T. W. Barrett. 2004. Is maximizing protection the same as minimizing loss? Efficiency and retention as alternative measures of the effectiveness of proposed reserves. Ecology Letters 7:1035-1046.

ReVelle, C. S., J. C. Williams, and J. J. Boland. 2002. Counterpart models in facility location science and reserve selection science. Environmental Modeling \& Assessment 7:71-80.

Rodrigues, A. S. L., and K. J. Gaston. 2001. How large do reserve networks need to be? Ecology Letters 4:602-609.

Rosenzweig, M. L. 1996. Species diversity in space and time. Cambridge University Press, Cambridge, UK.

Santelmann, M. V., D. White, K. Freemark, J. I. Nassauer, J. M. Eilers, K. B. Vache, B. J. Danielson, R. C. Corry, M. E. Clark, S. Polasky, R. M. Cruse, J. Sifneos, H. Rustigian, C. Coiner, J. Wu, and D. Debinski. 2004. Assessing alternative futures for agriculture in Iowa, USA. Landscape Ecology 19:357-374.

Schmoldt, D. L., and D. L. Peterson. 2000. Analytical group decision making in natural resources: methodology and application. Forest Science 46:62-75.
Schwartz, M. W., N. L. Jurjavcic, and J. M. O'Brien. 2002. Conservation's disenfranchised urban poor. Bioscience 52:601-606.

Scott, J. M., F. Davis, B. Csuti, R. Noss, B. Butterfield, C. Groves, H. Anderson, S. Caicco, F. Derchia, T. C. Edwards, J. Ulliman, and R. G. Wright. 1993. Gap analysis: a geographic approach to protection of biological diversity. Wildlife Monographs 123:1-41.

Sierra Nevada Ecosystem Project. 1996. Final report to Congress. Volume 1. Assessment summaries and management strategies. Centers for Water and Wildlands Resources, University of California, Davis, California, USA. Available online at http://ceres.ca.gov/snep/pubs/web/v1/v1 default.html.

Soule, M. E. 1991. Theory and strategy. Pages 91-104 in W. E. Hudson, editor. Landscape linkages and biodiversity. Island Press, Washington, D.C., USA.

Spero, J. G. 2001. Development and fire trends in oak woodlands of the northwestern Sierra Nevada foothills. U.S. Forest Service General Technical Report PSW-GTR-184. Available online at: http:// danr.ucop.edu/ihrmp/proceed/spero.pdf.

Steinitz, C. 1990. A framework for theory applicable to the education of landscape architects (and other design professionals). Landscape Journal 9:136-143.

Stoms, D. M. 1994. Scale dependence of species richness maps. Professional Geographer 46:346-358.

Theobald, D. M., and N. T. Hobbs. 2002. A framework for evaluating land use planning alternatives: protecting biodiversity on private land. Conservation Ecology 6(1): 5. [online] URL: http:/ /www.consecol.org/vol6/iss 1/art5/.

Theobald, D. M., N. T. Hobbs, T. Bearly, J. A. Zack, T. Shenk, and W. E. Riebsame. 2000. Incorporating biological information in local landuse decision making: designing a system for conservation planning. Landscape Ecology 15:35-45.

Theobald, D. M., J. R. Miller, and N. T. Hobbs. 1997. Estimating the cumulative effects of development on wildlife habitat. Landscape and 
Urban Planning 39:25-36.

Trousdale, W., and R. Gregory. 2004. Property evaluation and biodiversity conservation: decision support for making hard choices. Ecological Economics 48(3):279-291. Available online at: htt p://econpapers.repec.org/article/eeeecolec/

v 3A48 3Ay 3A2004 3Ai 3A3 3Ap 3A279-291. $\underline{\mathrm{htm}}$.

U.S. Census Bureau. 2002. TIGER/Line files: technical documentation. Geography Division, U. S. Census Bureau, Washington, D.C., USA.

U.S. General Accounting Office. 1998. Appraisals of headwater forest properties. Report to Congressional Committees GAO/RCED-99-52. U. S. General Accounting Office, Washington, D.C., USA.

Wallington, T. J., R. J. Hobbs, and S. A. Moore. 2005. Implications of current ecological thinking for biodiversity conservation: a review of the salient issues. Ecology and Society 10(1):15. [online] URL: http://www.ecologyandsociety.org/vol0/iss1/ $\underline{\operatorname{art} 15 / .}$

White, D., P. G. Minotti, M. J. Barczak, J. C. Sifneos, K. E. Freemark, M. V. Santelmann, C. F. Steinitz, A. R. Kiester, and E. M.Preston. 1997. Assessing risks to biodiversity from future landscape change. Conservation Biology 11:349-360.

Williams, P. H., and M. B. Araujo. 2000. Using probability of persistence to identify important areas for biodiversity conservation. Proceedings of the Royal Society of London Series B-Biological Sciences 267:1959-1966. 